\title{
Influence of Low Temperatures on the Mechanical Properties of 18:8 Chromium-Nickel Steel
}

\author{
By D. J. McAdam, Jr., G. W. Geil, and Frances Jane Cromwell
}

\begin{abstract}
By means of tension tests of notched and unnotched specimens, an investigation has been made of the mechanical properties of various 18:8 chromium-nickel steels between room temperature and $-188^{\circ} \mathrm{C}$. One of the steels was ferritic; the others were of the metastable austenitic type. Plastic deformation of the metastable austenitic alloys causes a phase change and thus hardens the alloy. The rapidity of this change increases with decrease in temperature. At low temperatures the hardening due to the phase change is so rapid that the load-extension curve sometimes has two maxima. For this reason six important strength indices sometimes are required to evaluate the mechanical properties.
\end{abstract}

\section{Introduction}

In a series of papers, the authors and their associates have presented results of a general investigation of the influence of low temperatures on the mechanical properties of ferrous and nonferrous metals [6 to 11]. ${ }^{1}$ However, the only steels studied were ferritic, and the only stainless steel was a $13: 2$ chromium-nickel steel $[6,7]$. Of the chromium-nickel alloys generally classed as austenitic there are two groups; in one group, the austenite is stable at room temperature; in the other group, the austenite is metastable. When alloys of the metastable, or "marginal", group are cooled rapidly from about $1,900^{\circ} \mathrm{F}$, they are austenitic, but the austenite tends to change partially to ferrite when the alloy is plastically deformed at room temperature or is reheated above $1,000{ }^{\circ} \mathrm{F}$ and subsequently cooled slowly. Although metastability of these alloys is disadvantageous for some types of service, their strength and toughness make them suitable for many types of service, especially when good corrosion and oxidation resistance is required.

One of the most important of the marginal alloys contains about 18 percent of chromium and 8 percent of nickel and is generally known as 18:8 chromium-nickel steel. Generally the chromium content ranges between 17 and 19, and the nickel content between 7 and 9 percent. As the space

\footnotetext{
${ }^{1}$ Figures in brackets indicate the literature references at the end of this paper.
}

lattice of chromium is body-centered and that of nickel is face-centered, an increase in the chromium content tends to make the alloy ferritic, and an increase in the nickel content tends to make it austenitic. For steels containing 18 percent of chromium, about 13 to 15 percent of nickel generally is necessary to make them stable at room temperature. The boundary between the stable and marginal group, however, depends on the percentage of carbon, manganese, and other alloying elements that may be added for special uses. It depends also on the temperature.

As shown by Aborn and Bain [1], Pilling [13] and others, the 18:8 alloy at room temperature would be completely stable only as a mixture of ferrite and carbides. ${ }^{2}$ Although rapid cooling of the commercial $18: 8$ alloy from about $1,900^{\circ} \mathrm{F}$ prevents the transformation of the austenite to ferrite, some ferrite will be formed subsequently if the alloy is deformed plastically at room temperature. Because the ferrite thus formed contains carbon in supersaturated solution, it is sometimes called martensite [13]. In future reference to this phase, however, it will be designated as ferrite. During long exposure of the 18:8 alloy to elevated temperatures, the metastability of the alloy manifests itself by precipitation of carbides.

Krivobok and Lincoln [5] investigated a series of alloys of the 18:8 type. The chromium content ranged from about 17 to 19 percent and the nickel

\footnotetext{
${ }^{2}$ Complete stability could be obtained only by cooling the steel at a very
} slow rate, requiring a cooling period much longer than is practical. 
from 7 to 9 percent. Moreover, there were two series with different carbon contents; the alloys of one series contained about 0.05 percent, and those of the other series contained about 0.15 percent of carbon. They studied the effect of composition on the mechanical properties of annealed strip and of strip that had been coldrolled various amounts. The ultimate stress and the ductility were found to vary greatly with the composition. They also discuss the influence of composition on the stability of the austenite.

Pilling [13] compared the rate of work-hardening of an 18:8 alloy with that of an 18:14 alloy and found that the 18:8 alloy hardened much more rapidly because of a greater precipitation of ferrite. Pfeil and Jones [14] compared the rates of workhardening of 18:8, 18:15, and 18:29 alloys, and also studied the variation of the work-hardening with carbon content. They found that the 18:8 alloy hardened more rapidly than the others. They also found that the rate of work-hardening of the 18:8 alloy increased greatly with increase in the carbon content, whereas the rate of workhardening of the other alloys was affected very little. However, other investigators [15, 18] have reported results obtained with an 18:8 alloy in which the rate of work-hardening varied little or decreased with increase in the carbon content.

Austin and Miller [2] studied the magnetic permeability of chromium-nickel stainless steels. In the austenitic state an alloy of the 18:8 type, an 18:12 alloy, and a 25:12 alloy were found to have practically the same magnetic permeability, about 1.003. With cold-work the increase in permeability was rapid for the 18:8 alloy, was much less rapid for the 18:12 alloy, and was negligible for the 25:12 alloy. The permeability of the 25:12 alloy was practically unchanged after 90 -percent reduction in area of the cross section.

Post and Eberly [15] studied the change in magnetic permeability with cold work as affected by variations in the percentages of chemical elements in the alloy. The chromium ranged from 13.9 to 24.3 percent, nickel from 7.75 to 20.65 , carbon from 0.03 to 0.20 , manganese from 0.4 to 3.92 , molybdenum up to 2.4 , titanium up to 0.5 , and columbium up to 1.0 percent. An empirical formula was developed to show the percentage of nickel necessary to make an alloy stable when cold-worked to 80-percent reduction in cross section. As carbon, manganese, and molybdenum have a marked effect on the stability of austenite, constants for these elements are included in the formula. Titanium and columbium decrease the stability of austenite. Manganese is about half as effective as nickel in austenite-forming tendency, and molybdenum is one and one-half times as effective as chromium in ferrite-forming tendency. The formula developed, however, is based entirely on results of experiments at room temperature. The results of the present investigation will show that the formula does not apply to these alloys at low temperatures. The percentage of nickel necessary to cause stability varies with the temperature.

Uhlig [19] showed that nitrogen, which is present in the commercial 18:8 alloys, inhibits the change from austenite to ferrite at room temperature. If a heat is prepared free from nitrogen, it will be partly ferritic even when quenched from $2,100^{\circ} \mathrm{F}$. If the carbon is also reduced to a negligible amount, the quenched alloy is almost entirely ferritic. With free access of air during melting, alloys with high chromium content absorb enough nitrogen to have a great effect on their properties.

When high strength is needed for a stable or marginal austenitic alloy, it can be obtained only by cold-work. On the other hand, Smith, Wycke, and Gorr [17] have developed a ferritic alloy of approximate 18:8 composition, which can be strengthened by precipitation-hardening. The austenite-forming and ferrite-forming elements are balanced so that the austenite transforms spontaneously to ferrite during about 4 hours after the alloy has been air-cooled from $1,900^{\circ}$ F. The ferrite thus formed contains carbon and other elements in supersaturated solution. When the alloy is heated at $900^{\circ}$ to $1,000^{\circ} \mathrm{F}$, it is hardened by particle-precipitation. The precipitate has not yet been identified, but the most important element associated with the precipitation-hardening is titanium. If the titanium content is less than 0.4 percent, the alloy may remain partly austenitic at room temperature; if the content is more than 1.0 percent, precipitationhardening will be excessive, and the ductility will be too low. Aluminum is added primarily as a deoxidizer, but the excess remaining in the alloy augments the precipitation-hardening effect of the titanium.

The influence of low temperatures on the prop- 
erties of ferrous and nonferrous metals has been investigated by Colbeck, MacGillivray, and Manning [3]. An 18:8 chromium-nickel steel was included in their investigation. They report values for the yield stress, ultimate stress, and reduction of area at various temperatures between room temperature and the temperature of liquid air, but they give no values for the breaking stress. DeHaas and Hadfield [4] reported values for the same properties at room temperature and at the temperature of liquid hydrogen $\left(-252.8^{\circ} \mathrm{C}\right)$. Their values for ultimate stress are shown in figure 15, which will be discussed later.

Rosenberg [16] studied the tensile and impact properties of aircraft metals, including various alloys of the 18:8 type, at temperatures down to $-78^{\circ} \mathrm{C}$. In addition to plain 18:8 alloys, there were alloys containing small percentages of elements that are customarily added to prevent local depletion of chromium by carbide precipitation at elevated temperatures. Specimens from some of these heats of steel have been included in the investigation to be described in this paper, and a few of the results obtained by Rosenberg have been plotted in some of the figures.

The literature on the properties of the chromiumnickel stainless steels is confined mainly to the study of the properties of the alloys at room temperatures and at elevated temperatures. Very little work has been reported on the mechanical properties of these alloys at low temperatures, and in these reported investigations insufficient information is supplied on the flow stresses, breaking stresses, and fracture of the alloys. In recent years there has been increasing need for additional information about the influence of temperature down to that of liquid air on the properties of these alloys. The present paper gives the results of an investigation of the effect of temperature, ranging from room temperature to that of liquid air, on the mechanical properties of $18: 8$ chromium-nickel alloys. The results obtained in this study also reveal the influence of plastic deformation and temperature on the transformation from austenite to ferrite and give information applicable qualitatively to the entire group of metastable alloys, including those that are much nearer than the 18:8 alloy to the boundary between the metastable and the stable austenitic group. An alloy of the ferritic 18:8 steel of the precipitation hardening type also was included in this study.

\section{Materials, Method of Investigation, and Specimens}

The alloys used in this investigation were all of the 18:8 type; the chemical compositions are given in table 1. The compositions of all but one of the alloys were such that the alloys were austenitic after quenching from $1,900^{\circ} \mathrm{F}$; the alloy designated $E H$ in table 1 becomes ferritic after quenching from $1,900^{\circ} \mathrm{F}$, and can then be hardened by reheating to cause precipitation. The heat treatments given to these alloys are described in table 2 .

Table 1. Description of steels

\begin{tabular}{|c|c|c|c|c|c|c|c|c|c|}
\hline \multirow[b]{2}{*}{$\begin{array}{c}\text { Material } \\
\text { designation }\end{array}$} & \multicolumn{9}{|c|}{ Chemical composition } \\
\hline & $\begin{array}{l}\text { ేี } \\
\frac{0}{\tilde{\Xi}} \\
0\end{array}$ & 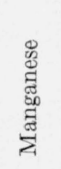 & 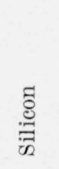 & 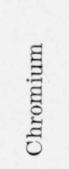 & $\begin{array}{l}\vec{D} \\
\frac{y}{0} \\
\dot{y}\end{array}$ & $\begin{array}{l}\text { J } \\
\Xi \\
0 \\
0 \\
0 \\
\frac{0}{3} \\
\frac{0}{J}\end{array}$ & 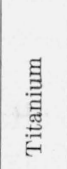 & 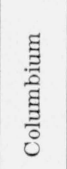 & 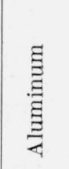 \\
\hline & $\begin{array}{l}\text { Per- } \\
\text { cent }\end{array}$ & $\begin{array}{l}\text { Per- } \\
\text { cent }\end{array}$ & $\begin{array}{l}\text { Per- } \\
\text { cent }\end{array}$ & $\begin{array}{l}\text { Per- } \\
\text { cent }\end{array}$ & $\begin{array}{l}\text { Per- } \\
\text { cent }\end{array}$ & $\begin{array}{l}\text { Per- } \\
\text { cent }\end{array}$ & $\begin{array}{l}\text { Per- } \\
\text { cent }\end{array}$ & $\begin{array}{l}\text { Per- } \\
\text { cent }\end{array}$ & $\begin{array}{l}\text { Per- } \\
\text { cent }\end{array}$ \\
\hline$E A$ & 0.07 & 0.44 & 0.50 & 18. 22 & 8. 63 & & & & -.... \\
\hline$E B$ & .10 & .47 & .35 & 18. 82 & 9.38 & & & & \\
\hline$E C_{\ldots}$ & .05 & .39 & .62 & 19.04 & 9.15 & & 0. 29 & & \\
\hline$E E \ldots$ & .075 & .64 & .61 & 18. 61 & 10. 16 & - . . & & 0.93 & -. \\
\hline$E F$ & .07 & .93 & .42 & 18. 58 & 8.93 & 3.36 & & & \\
\hline$E G_{\ldots}$ & .07 & .73 & .48 & 18. 41 & 7.88 & 2.80 & & & $\ldots$ \\
\hline$E H$ & .07 & .50 & .50 & 17.00 & 7. 00 & & .70 & & 0.20 \\
\hline
\end{tabular}

TABLE 2. Heat treatment of steels

\begin{tabular}{|c|c|c|c|c|}
\hline Material designation & $\begin{array}{l}\text { Rod di- } \\
\text { ameter }\end{array}$ & $\begin{array}{l}\text { Temper- } \\
\text { ature }\end{array}$ & $\begin{array}{l}\text { Time } \\
\text { held }\end{array}$ & Cooled in- \\
\hline $\begin{array}{l}E A \text { to } E E \\
E F\end{array}$ & $\begin{array}{l}\text { in } \\
0.625 \\
.625\end{array}$ & $\begin{array}{l}{ }^{\circ} F \\
1,900 \\
(a)\end{array}$ & $h r_{1}$ & Water. \\
\hline $\mathrm{EH}$ & 1.000 & $\left\{\begin{array}{l}1,900 \\
1,000\end{array}\right.$ & $\begin{array}{l}1 / 2 \\
3 / 4\end{array}$ & $\begin{array}{l}\text { Air. } \\
\text { Water. }\end{array}$ \\
\hline
\end{tabular}

a Annealed by manufacturer.

The alloys were received in the form of round rods of the sizes indicated in table 2 . The rods of one of the alloys, designated by EF in table 1, had been annealed by the manufacturer. The annealing treatment doubtless was about the same as the austenitizing treatment given to alloys $E A$ to $E E$ (table 2). The rods of the other alloys were in cold-drawn condition; the rods of two of the 
alloys $(E B$ and $E E)$ had been drawn two different amounts.

For a description of the apparatus and the methods of testing at low temperatures, reference may be made to a previous paper [6]. Most of the specimens used in this investigation were unnotched and of standard form. Deeply notched cylindrical specimens, however, were also used in obtaining the diagrams in figure 16 . The notches were all about the same depth $(k=$ about 0.16$),{ }^{3}$ but the notch angle varied between $150^{\circ}$ and $50^{\circ}$. The notched specimens were about $5 \frac{1}{1} 2$ ins. long. The ends of the specimens were threaded to $5 / 8$-in. diameter. Between the threaded ends, the specimen was machined to a uniform diameter of $5 / 8$ in., and a circumferential $V$-notch was machined at the midsection. The notch was carefully machined to the selected angle, with the conical sides tangent to the arc at the root of the notch. Care was also taken to minimize heating, bending, or appreciable cold work during the machining.

The results are presented in diagrams of three types. Diagrams of the first type (figs. 1 to 3 ) show the influence of extension on the nominal stress, the load divided by the initial area of cross section. Diagrams of the second type (figs. 4 to 8 ) show the variation of the stress with the true strain. Diagrams of the third type (figs. 9 to 16) show how the strength indices of these alloys vary with temperature.

\section{Variation of the Nominal Stress with Tensile Extension}

Automatic load-extension diagrams obtained in the tension tests of the 18:8 chromium-nickel steels gave clear evidence of phase changes during the plastic deformation. Typical curves derived from automatic load-extension diagrams obtained with unnotched specimens are shown in figures 1,2 , and 3. ${ }^{4}$ These curves show the influence of plastic extension on the nominal stress, that is, the stress value obtained by dividing the tensile load by the initial area of cross section.

\footnotetext{
${ }^{3}$ Notch depth is expressed in terms of the relative area $\left(k=b^{2} / B^{2}\right)$ of the minimum cross section, where $b$ and $B$ represent the radii of the minimum and maximum cross section, respectively. Thus, the greater the notch depth, the smaller is the value of $k$.

${ }^{4}$ No actual points, except those for the final breaking stresses, are shown in the derived diagrams of figures 1,2 , and 3 . The use of symbols or plotted points along the curves would tend to obscure the abrupt changes that occur, especially for the $-78^{\circ} \mathrm{C}$ and $-188^{\circ} \mathrm{C}$ curves.
}

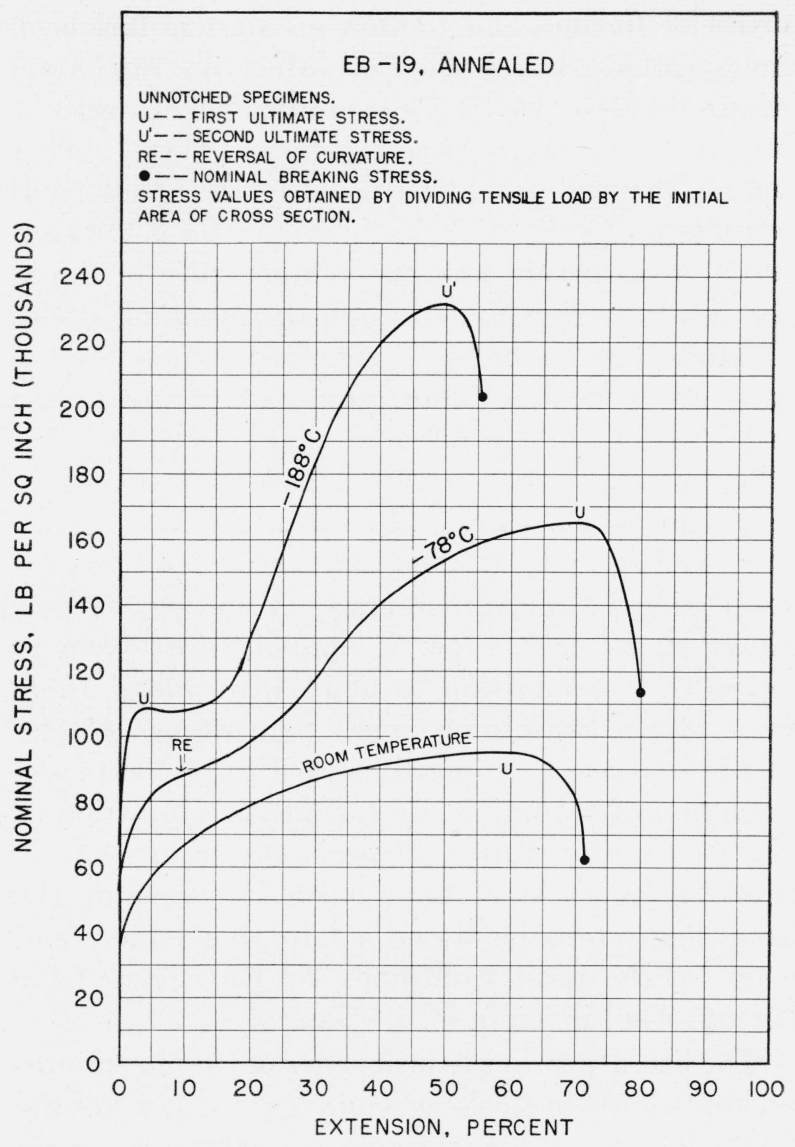

FIgURE 1. Variation of nominal stress with extension, annealed 18:8 chromium-nickel steel, plain.

Figure 1 shows results of tension tests of annealed austenitic plain 18:8 alloy at three different temperatures. The curve obtained at room temperature is qualitatively similar to a curve obtained without phase change. The slope decreases continuously between the points representing yield and maximum load. Transformation from austenite to ferrite during plastic deformation at room temperature evidently was not sufficient to cause a qualitative change in the form of the curve. The curve obtained at $-78^{\circ} \mathrm{C}$, however, gives clear evidence of a rapid phase change during the tension test. The reversal of curvature and the rapid increase in slope beyond the point of reversal $(R E)$ indicates that the strengthening during plastic extension was due not only to ordinary work-hardening, but also to hardening caused by transformation of austenite to ferrite supersaturated with carbon. The hardening caused by this phase change possibly is not due merely to the difference in hardness between the ferrite and 
austenite; it may be due partly to precipitation of fine particles of the ferrite within the austenite grains, or to precipitation of carbides.

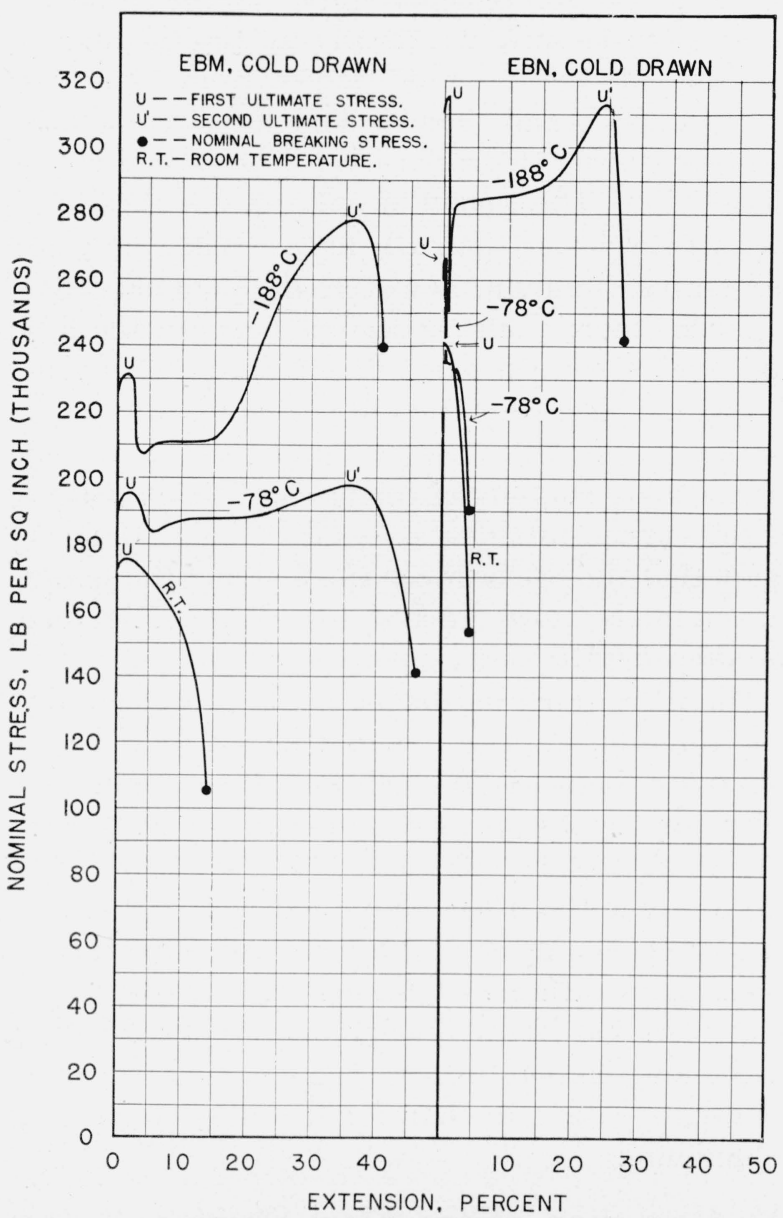

FIGURE 2. Variation of nominal stress with extension, cold-drawn 18:8 chromium-nickel steels, plain.

The curve obtained at $-188^{\circ} \mathrm{C}$ reveals still more clearly the combined influences of work hardening and the hardening caused by phase change. This curve, like the curves obtained at room temperature and at $-78^{\circ} \mathrm{C}$, shows no abrupt yield point; from the region representing the beginning of plastic strain, the curve rises with continuously decreasing slope to the maximum designated by. $U$. The descent beyond $U$ represents the effect of incipient local contraction. In the absence of a phase change, the local contraction would have continued, and the curve would have descended with increasing slope to a point representing fracture. However, the local contraction and consequent descent of the curve evidently was stopped by a rapid phase change.

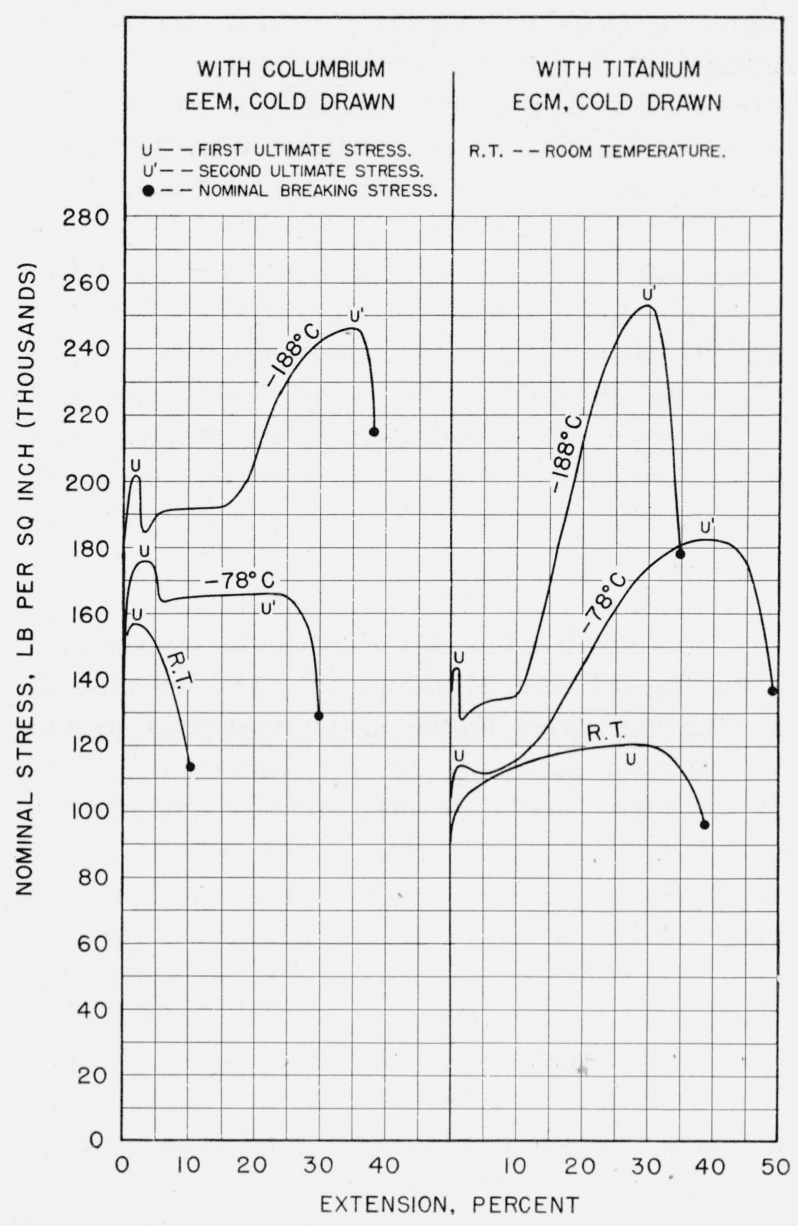

Figure 3. Variation of nominal stress with extension, cold-drawn 18:8 chromium-nickel steels.

The influence of the hardening due to the phase change then became dominant and caused the rise of the curve from the minimum to a second maximum designated by $U^{\prime}$. This point indicates the beginning of final local contraction.

The ordinates of points $U$ and $U^{\prime}$, therefore, represent first and second ultimate stresses. The final local contraction beginning at the second maximum of the tensile load is not necessarily in the same place as the incipient local contraction at the first maximum. Specimens examined after fracture at low temperatures often show evidence of slight local contraction at a distance from the region of final contraction.

Figure 2 shows results obtained with colddrawn-rods of the same alloy that was used in obtaining figure 1. The metal designated $E B M$ in figure 2 was moderately cold-drawn to approximately 49-percent reduction of area, and the metal 
designated $E B N$ was severely cold-drawn to approximately 71-percent reduction of area. The curves obtained at room temperature are similar in form to the curve obtained at room temperature with the annealed alloy; there are no reversals in curvature or second maxima. As would be expected, however, the extension at the maximum load was much less for the moderately cold-drawn metal $E B M$ than for the annealed metal, and there was practically no extension at the maximum load for the severely cold-drawn metal $E B N$. The curves obtained at room temperature, therefore, are qualitatively similar to curves obtained without phase change.

Comparison of the curves obtained at $-188^{\circ} \mathrm{C}$ with the annealed metal and with the cold-drawn metals (figs. 1 and 2) shows that the increase in the nominal stress between the first and second maximum is greatest for the annealed metal, $E B-19$, and least for the severely cold-drawn metal $E B N$. A part of these differences is due to corresponding differences in ordinary work hardening between the first and second maximum, but more is due to the differences in the hardening caused by phase changes. The greater the plastic deformation at room temperature, the less is the combined influence of ordinary workhardening and the hardening due to phase change during plastic deformation at $-188^{\circ} \mathrm{C}$.

As previously stated, columbium or titanium sometimes is added to 18:8 alloys to prevent the precipitation of chromium-rich carbides at elevated temperatures, and the resultant local depletion of the chromium in solid solution. The strong affinity of columbium and titanium for carbon, however, tends indirectly to decrease the stability of the austenite at low temperatures. Figure 3 shows results of tension tests of two cold-drawn 18:8 alloys, one containing columbium and the other containing titanium. Comparison of the curves obtained at room temperature shows that alloy $E C M$ had been less severely cold-drawn than alloy EEM. The ultimate stress was much lower, and the extension at the maximum load was much greater for alloy ECM than for alloy EEM. Moreover, both these alloys evidently had been less severely cold-drawn than the moderately cold-drawn plain 18:8 alloy, $E B M$ (fig. 2).

The curves obtained at $-78^{\circ} \mathrm{C}$ with alloys $E C M$ and EEM (fig. 3) differ greatly. Although both curves reveal clearly the hardening effect of ferrite precipitation, the effect was more prominent with the alloy containing titanium. With the alloy containing columbium, the precipitation hardening was sufficient merely to stop the abrupt decrease of the nominal stress from the first maximum $(U)$ and then to hold the stress nearly constant during the extension to the second maximum $\left(U^{\prime}\right)$. The second ultimate stress, therefore, was a little lower than the first. With the alloy containing titanium, however, the nominal stress increased more than 50 percent between the first and second maximum. Precipitation of ferrite during the plastic deformation evidently was much more rapid for the alloy containing titanium than for the alloy containing columbium. Comparison of the curves obtained at $-188^{\circ} \mathrm{C}$ (fig. 3) shows again that the rise between the first and the second maximum is much greater for alloy $E C M$ than for alloy EEM.

The more rapid hardening of the alloy containing titanium, however, cannot be attributed to a difference between the effects of titanium and columbium. As previously shown, the alloy containing titanium had been less severely colddrawn than the other alloy, and hence the precipitation of ferrite during the cold-drawing at room temperature had been less. Consequently both work-hardening and precipitation hardening at the low temperatures were greater for the alloy containing titanium than for the alloy containing columbium.

\section{Variation of the Flow Stress with the True Strain}

Curves of the type shown in figures 1, 2, and 3 are important because they show how the load varies during a tension test, but they do not show how the "true stress" varies with plastic strain, nor do they represent correctly the variation of the strain after the beginning of local contraction. Therefore, in diagrams of the type now to be considered, ordinates represent true stresses and abscissas represent true strains. Figures 4 to 8 show diagrams of this type. Each curve in these figures shows the influence of plastic strain on the "flow stress," which is the true tensile stress at any instant during flow of the metal. Strain is represented in terms of $A_{0} / A,{ }^{5}$ in which $A_{0}$

${ }_{5}^{5}$ The ratio $A_{0} / A$ is designated the effective length ratio and represents the ratio of current to original length, had the specimens contracted uniformly at the same rate as at its minimum cross section. 
and $A$ represent the initial and current areas of cross section. Values of $A_{0} / A$ are represented on a logarithmic scale; therefore, true strain, which is defined as $\log _{\mathrm{e}} A_{0} / A$, would be measured linearly on this scale.

The results of tension tests represented in figures 1,2 , and 3 are represented again in the diagrams of a different type in figures 4,5 , and 6 , respectively. During the tension tests at room temperature the change in the diameter of the specimen was measured at frequent intervals, and measurement was continued almost to the beginning of fracture. The small open circles along the flowstress curves represent the results of measurements during flow, and the end of each curve obtained at room temperature represents the true fracture stress, the stress at the beginning of

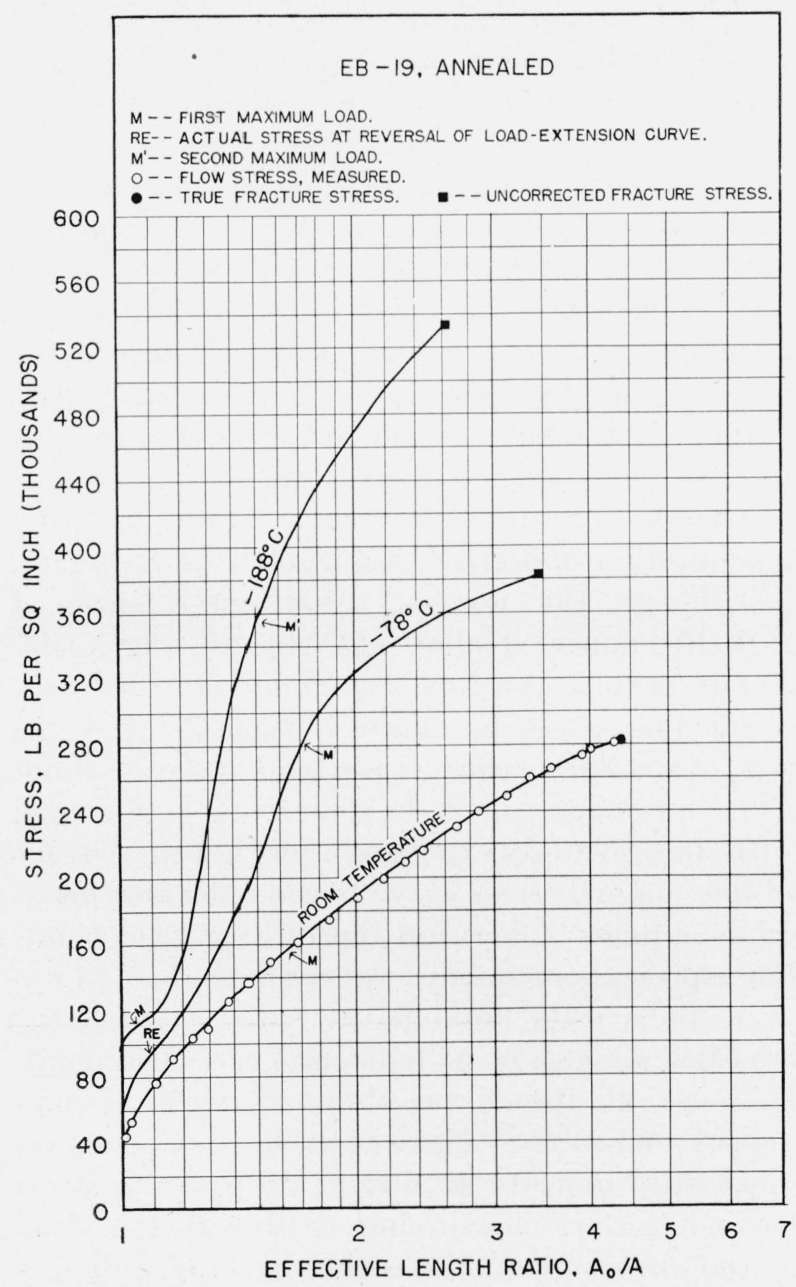

FIGURE 4. Variation of true stress with strain, annealed 18:8 chromium-nickel steel, plain.

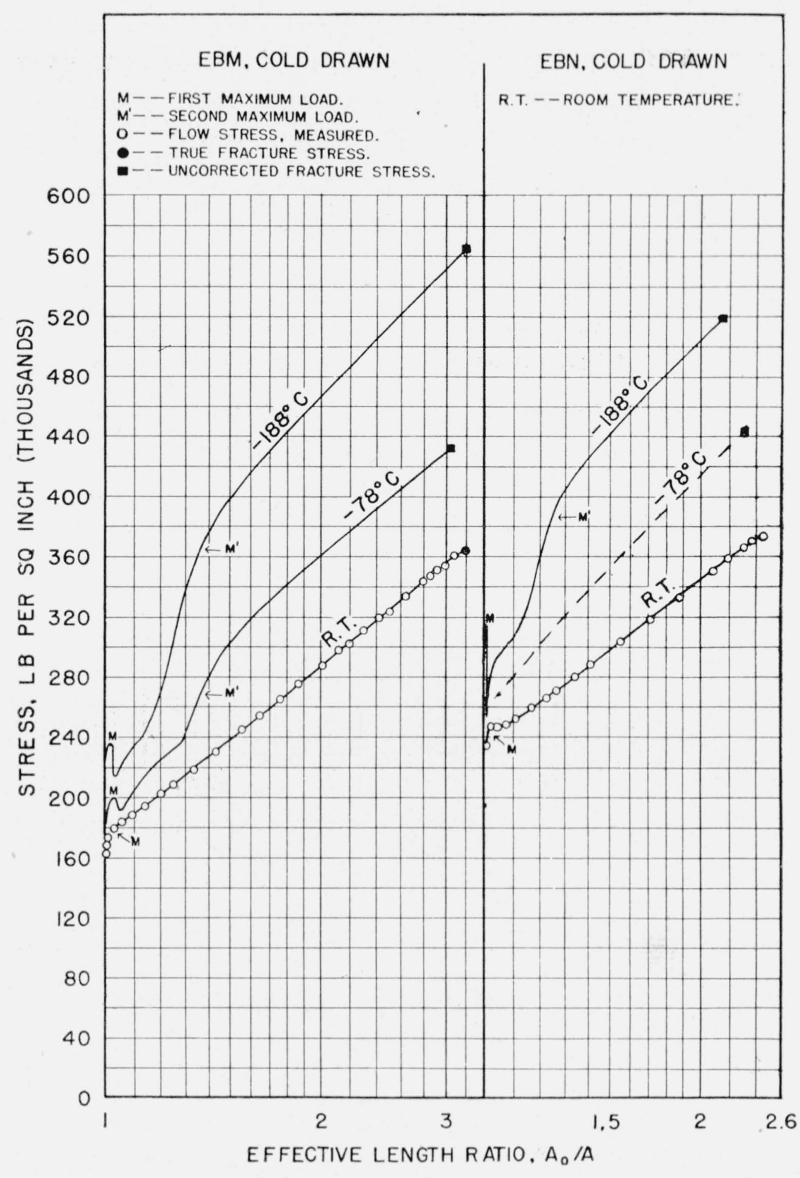

Figure 5. Variation of true stress with strain, cold-drawn 18:8 chromium-nickel steels, plain.

fracture. The fracture stresses were also determined in the usual way, by dividing the load at the beginning of fracture by the area of cross section measured after fracture. The area so determined is generally less than the area measured at the beginning of fracture, because the metal at the rim of the cross section continues to extend after fracture begins at the axis $[7,10,11]$. With these 18:8 chromium-nickel steels, however, the difference between the uncorrected fracture stress and the true fracture stress was slight, even at room temperature. The uncorrected fracture stresses of the alloys tested at room temperature, therefore, are not indicated in the figures.

During the tension tests at $-78^{\circ} \mathrm{C}$ and at $-188^{\circ} \mathrm{C}$, no transverse measurements of the specimen were made, and the fracture stresses were determined in the usual way, by dividing the tensile load at the beginning of fracture by the area of cross section measured after fracture. 
As the difference between the uncorrected fracture stress and the true fracture stress was slight even at room temperature, it probably was negligible at low temperatures. The uncorrected fracture stresses indicated in figures 4,5 , and 6 , therefore, probably are not far from the true fracture stresses.

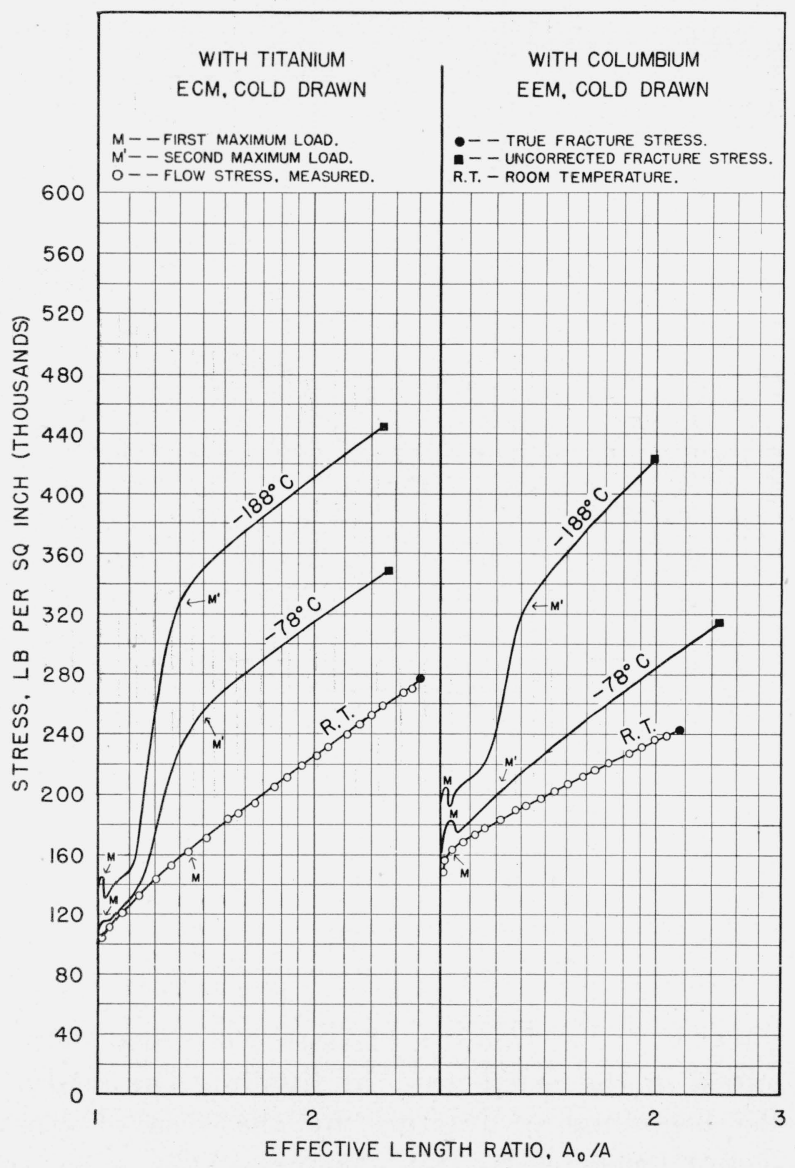

FIgURE 6. Variation of true stress with strain, cold-drawn 18:8 chromium-nickel steels.

As no transverse measurements of the specimens were made during the tests at $-78^{\circ} \mathrm{C}$ and $-188^{\circ} \mathrm{C}$, the flow-stress curves for these temperatures (figs. 4, 5, and 6) are derived from the corresponding curves representing the variation of the nominal stress with extension (figs. 1, 2, and $3)$. The derivation is based on the simplifying assumption that each specimen remains cylindrical during the extension to the beginning of final local contraction. This assumption implies that, during this extension, the percent difference between the flow stress and the nominal stress at any instant is equal to the percent extension. In this way, the flow-stress curves for $-78^{\circ} \mathrm{C}$ and $-188^{\circ}$
$\mathrm{C}$ in figures 4,5 , and 6 have been constructed between the point representing yield and the point representing the final maximum of the load. Because of the local contraction, the curve between the point representing the final maximum and the point representing fracture cannot be determined from a load-extension diagram. Between these points, however, the curves have been drawn to represent the probable approximate variation of the flow stress at $-78^{\circ} \mathrm{C}$ and $188^{\circ} \mathrm{C}$.

The flow-stress curve obtained with annealed plain 18:8 alloy at room temperature (fig. 4) is similar in form to curves obtained with metal that is free from phase change during plastic deformation. As shown in previous papers [10, 11], the flow-stress line obtained with some metals is nearly straight between the points representing maximum load and fracture, as in figure 6 , but the line obtained with many metals rises with continuously decreasing slope, as in figure 4. The flow-stress lines obtained at room temperature with the cold-drawn plain alloys (figure 5), rise with increasing slope, thus showing the effect of the precipitation-hardening during the plastic deformation. The flow-stress curves obtained at low temperatures, like the corresponding curves in figures 1,2, and 3, give clear evidence of the influence of phase change. The reversal of curvature and the steep ascent to the point representing the beginning of local contraction can be attributed only to the hardening caused by rapid precipitation of ferrite throughout the austenite.

Although the nominal-stress curve obtained with the annealed alloy at $-188^{\circ} \mathrm{C}$ (fig. 1) descends beyond the first maximum $(U)$, the corresponding curve in figure 4 indicates that the flow stress rises continuously with plastic strain. The continuous rise of the flow stress is in accord with the previously expressed view that the descent of the nominal-stress curve beyond the first maximum in figure 1 does not represent a yield point, but represents incipient local contraction. Moreover, the curves obtained at $-78^{\circ} \mathrm{C}$ with the annealed alloy show no indication of a yield point. However, all the curves obtained with the previously cold-worked alloys at the low temperatures apparently indicate an abrupt drop in the stress beyond the first maximum. Although this drop of the curves resembles somewhat the drop between the upper and lower yield points of ferritic steels, there are two reasons why the drop in the 
curves does not represent a yield point. One reason is that considerable plastic strain occurs during the test before the load reaches the first maximum, for all the alloys except the severely cold-drawn plain alloy $E B N$ (fig. 5). The other reason is that no suggestion of a yield was obtained with the annealed alloy (fig. 4). It seems probable, therefore, that there is no drop in the true flow stress for either an annealed or a cold-drawn 18:8 alloy. The strains plotted in figures 4,5 , and 6 are average true strains, calculated on the assumption that the specimens remained cylindrical during the extension to the beginning of final local contraction. Actually, however, the true strain in the region of incipient local contraction may be considerably greater than is indicated by the average extension of the specimen. Moreover, inertia effects probably accentuate the abrupt drop of the load from the first maximum. The true flow stress, therefore, probably rises continuously with the plastic deformation of either annealed or cold-drawn 18:8 alloys.

In figure 7, a comparison is made between a cold-drawn metastable austenitic alloy containing molybdenum and a precipitation-hardened alloy. The previously discussed composition of the precipitation-hardenable alloy $(E H)$, and the details of the heat treatment are given in tables 1 and 2 . As shown in figure 7 , the flow-stress curves obtained with the alloy (EGM) containing molybdenum are generally similar to the curves shown in figures 4,5 , and 6 . The ductility of the metastable austenitic alloys evidently is not seriously affected by the rapid hardening caused by the phase change during plastic deformation at low temperatures (figs. 4, 5, and 6). However, the effect of low temperatures on the ductility of the annealed plain 18:8 alloy (fig. 4) was greater than the effect on the cold-drawn alloys (fig. 5). The adverse effect of a low temperature on the ductility evidently is greater when all the plastic deformation is at the low temperature than when part of it is at room temperature. Precipitation of ferrite from the austenite, therefore, evidently has considerable effect on the ductility. The good ductility exhibited by these alloys at low temperatures may be due partly to retention of some of the austenite.

At room temperature, the flow stress curve for the ferritic alloy $E H-A-10$ (fig. 7) was higher than that for the moderately cold-drawn plain alloy

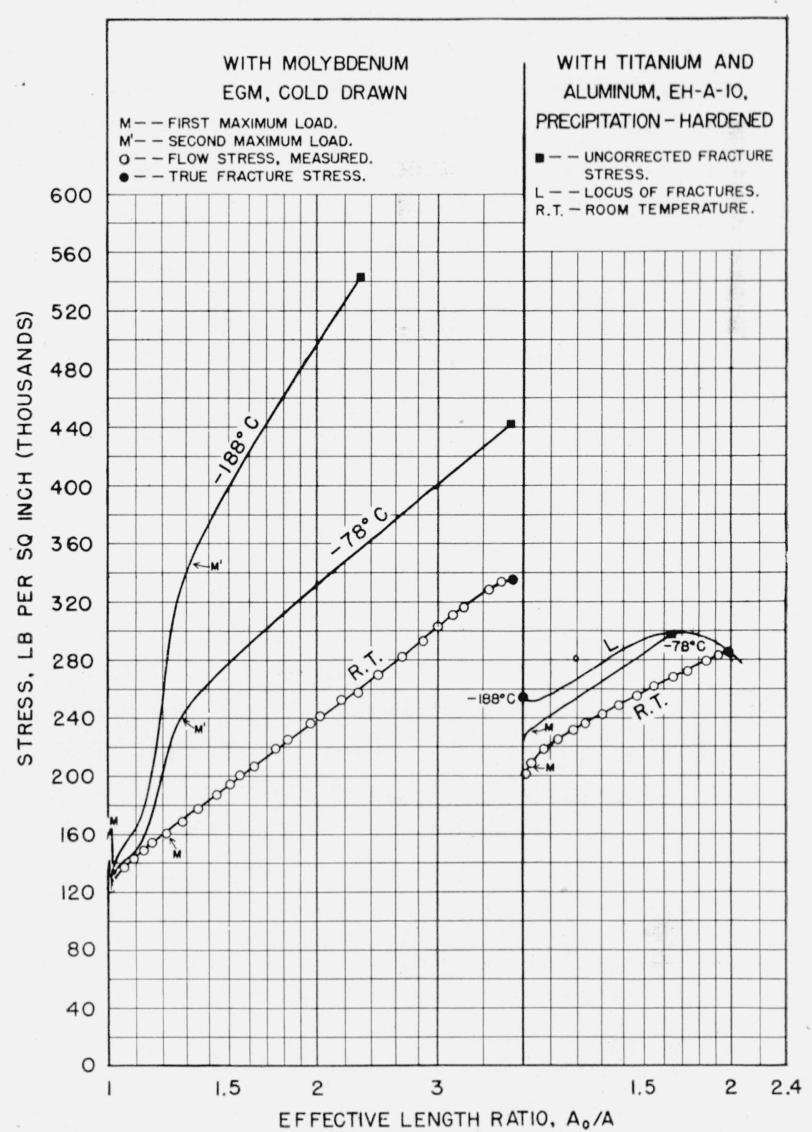

FiguRE 7. Variation of true stress with strain, 18:8 chromium-nickel steels.

$E B M$ (fig. 5) or the moderately cold-drawn alloys containing titanium, columbium, and molybdenum (figs. 6 and 7), but was lower than that for the severely cold-drawn plain alloy $E B N$ (fig. 5). The ductility of the ferritic alloy at room temperature (fig. 7) was a little less than that of any of the cold-drawn metastable austenitic alloys (figs. 5, 6, and 7 ). With decrease in temperature, the ductility of the ferritic alloy decreased rapidly, and a specimen tested at $-188^{\circ} \mathrm{C}$ showed no ductility. To make sure that the brittleness at that temperature was not due to some defect in the specimen, another specimen was tested; the result was the same. The effect of low temperatures on the ductility of this alloy, therefore, evidently is similar to the effect on the ductility of annealed low-carbon steels. For use at low temperatures, the ductility would possibly be improved if some austenite were retained along with the ferrite and the precipitated constituent. 
It has been shown that the influence of the total plastic deformation on the flow stress at a low temperature depends on the relative amounts of the plastic deformation at room temperature and at the low temperature. For a study of the influence of both the prior plastic deformation at room temperature and the total plastic deformation, results obtained with the same metal after various amounts of prior plastic deformation may be assembled in a single diagram, in which abscissas represent values of the total plastic deformation [12]. A diagram of this type is shown in figure 8 , which is derived by assembling flow-stress curves reproduced from figures 4 and 5 . Figure 8 thus represents the influence of total plastic deformation on the flow stress and fracture stress of a plain 18:8 chromium-nickel steel. As the true strains represented by the prior plastic deformation and the subsequent deformation during a tension test are directly additive, and inasmuch as the abscissa and ordinate scales in figure 8 are the same as in figures 4 and 5 , the flow-stress curves have been transferred directly from the basic diagrams to figure 8 . In such a transfer, however, it is necessary to place the origin of each curve at an abscissa representing the corresponding amount of prior plastic deformation. The two vertical dot-and-dash curves in figure 8 represent the amounts of prior plastic deformation given to alloys $E B M$ and $E B N$. Curve $F_{0}$ represents approximately the tensile flow-stress curve that would be obtained if the stress could be kept unidirectional. The local contraction of a tension test specimen induces transverse radial tensile stress, and the ratio of the transverse to the longitudinal stress (radial stress ratio) increases with the local contraction. Because of the increasing radial stress ratio, curve $F$ for the annealed alloy rises above the derived curve $F_{0}$. A method of deriving curve $F_{0}$ is described in a previous paper [12] in which the relation between curves $F_{0}$ and $F$ is shown in diagrams. In figure 8 , curve $F_{0}$ has been drawn so as to be in approximately correct relation to curve $F$ for the annealed alloy. It also has been drawn to pass through the first maximum points $M$ on the flow-stress curves obtained with the cold-drawn alloys $E B M$ and $E B N$ at room temperature. The diagram thus represents qualitatively the influence of prior and total plastic deformation and of low temperatures on the flow stress and fracture stress.

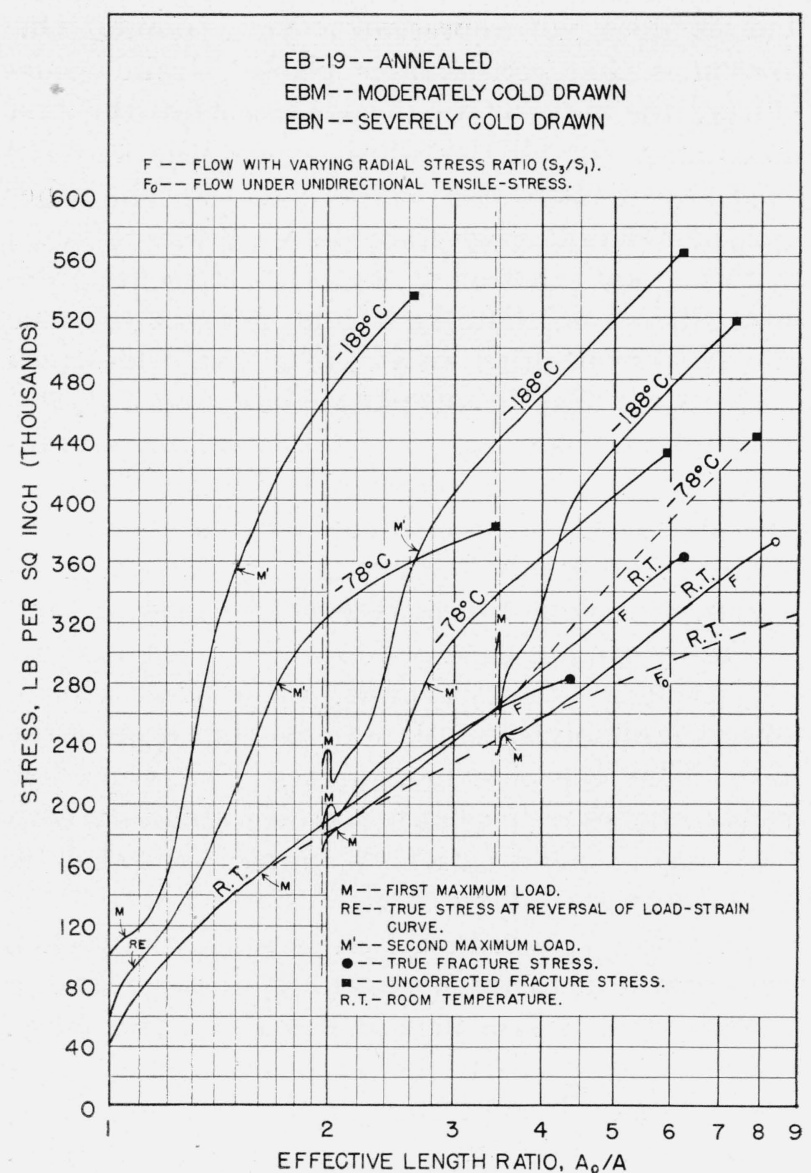

FIGURE 8. Influence of prior and total plastic deformation on flow stress and fracture stress of plain 18:8 chromiumnickel-steel.

The curves representing flow during local contraction at room temperature rise above curve $F_{0}$ because of increasing transverse radial tensile stress induced by the local contraction. A curve similar to curve $F_{0}$ could be drawn through points $M$ on the flow-stress curves obtained at $-188^{\circ}$ C. As points $M$ represent flow stresses after various amounts of plastic deformation at room temperature and only slight plastic deformation at $-188^{\circ} \mathrm{C}$, a curve drawn through points $M$ would approximately represent flow under unidirectional tensile stress entirely at $-188^{\circ} \mathrm{C}$, but with the requirement that the precipitationhardening was the same as at room temperature. A similar curve could be drawn to represent flow at $-78^{\circ} \mathrm{C}$. The more rapid rise of the flowstress curves obtained at $-78^{\circ} \mathrm{C}$ and $-188^{\circ} \mathrm{C}$ (fig. 8 ) is due to the more rapid precipitationhardening during flow at these temperatures. 
The rapid rise of these curves cannot be attributed to an increase in the radial stress ratio; the stress remains nearly unidirectional until the beginning of the final local contraction, designated by $M^{\prime}$.

The rapid precipitation-hardening during plastic deformation at low temperatures evidently increases the fracture stress nearly as rapidly as it increases the flow stress. If precipitationhardening were no more rapid at $-188^{\circ} \mathrm{C}$. than at room temperature, the point representing fracture in a test entirely at $-188^{\circ} \mathrm{C}$ would be on the previously discussed curve that could be drawn through the corresponding points $M$ in fig. 8 . With sufficient increase in the prior plastic deformation at room temperature, the fracture stress at a low temperature would begin to decrease because of the decrease in the relative amount of plastic deformation at the low temperature and the accompanying decrease in the amount of precipitation-hardening.

\section{Magnetic Changes with Plastic Deformation}

Reference has been made to several investigations of the change in magnetic properties of 18:8 alloys with plastic deformation $[1,2,13,15]$. In some investigations, quantitative studies of the transformation from austenite to ferrite have been made by measurement of magnetic permeability [2, 15]. None of the specimens used in these previous investigations, however, had been plastically deformed at low temperature. As the evidence in figures 1 to 8 shows that the hardening due to the phase change is more rapid at low temperatures than at room temperature, a brief qualitative investigation has been made to determine if these differences in precipitationhardening could be correlated with changes in magnetism. For this purpose typical specimens that had been used in tension tests represented in figures 4 to 7 were explored by means of a small strong horseshoe magnet. These specimens included annealed, moderately cold-drawn, and severely cold-drawn metals. Some had been tested to fracture at room temperature, and some had been tested at low temperatures.

The specimens that had been tested to fracture at room temperature were slightly magnetic at the surface of fracture and in the adjacent locally contracted region, but the magnetic attraction was hardly noticeable elsewhere along the specimen.
Moreover, the magnetic attraction was not appreciably greater for moderately cold-drawn than for annealed metal. The attraction was a little greater for specimens of severely cold-drawn metal, especially at the surface of fracture. However, the attraction was not strong enough to lift the specimens. The increase in magnetism in the locally contracted region is a result of the relatively large amount of plastic deformation occurring during the local contraction.

The specimens that had been tested at $-78^{\circ} \mathrm{C}$ and at $-188^{\circ} \mathrm{C}$ were only slightly magnetic at the threaded ends, which had not been plastically deformed at the low temperatures. Between the end fillet and the locally contracted region, however, each specimen was strongly magnetic; the attraction was strong enough to lift some specimens attached to both poles of the magnet. At the surface of fracture, the attraction was so strong that each specimen could be vertically suspended from one pole of the magnet. The magnetic attraction along the plastically extended side of the specimen, however, evidently was not as strong for the severely cold-drawn specimens as for the moderately cold-drawn or annealed specimens. The weaker magnetic attraction for the severely cold-drawn alloy may be correlated with the relatively smaller amount of plastic deformation at low temperature. The method of investigation was not sensitive enough to detect differences in magnetism between specimens of annealed metal and specimens of moderately cold-drawn metal, or to detect differences between specimens that had been plastically deformed at $-78^{\circ} \mathrm{C}$ and those that had been deformed at $-188^{\circ} \mathrm{C}$.

The results of these qualitative magnetic tests confirm the previously expressed view that the rapid rise of the flow-stress with plastic deformation at low temperatures (figs. 4 to 8 ) is due to a. rapid transformation of austenite to ferrite.

\section{Variation of Strength Between Room Temperature and $-188^{\circ} \mathrm{C}$}

Consideration will now be given to diagrams of a. different type. In these diagrams, which are shown in figures 9 to 16 , temperatures are plotted as abscissas, and indices of strength are plotted as ordinates. In these figures, the temperature scale is the same that has been used in previous papers by the authors and their associates $[6$ to 10]. Temperatures in degrees $K$ are plotted on a 
logarithmic scale. As abscissas are proportional to the logarithm of the degrees $\mathrm{K}$, the scale is the same in principle as Kelvin's original thermodynamic scale. This scale has been used because, as has been shown [6 to 10], it gives a linear relationship between temperature and the strength indices for various metals in the absence of phase changes.

The strength of most metals can be evaluated by the use of only three indices, namely, the yield stress, ultimate stress, and fracture stress. For 18:8 chromium-nickel steels at low temperatures, however, six strength indices are important, although sometimes less than six are sufficient. As illustrated in figures 1 to 7 , these indices are: yield stress, first ultimate stress, stress at a minimum in the load-extension curve, stress at a reversal of the load-extension curve, second ultimate stress, and true fracture stress. All these indices and the true stress at the second maximum load have been used in figures 9 to 14 . Nominal-stress values, such as those represented in figures 1 to 3 , have been used for the first ultimate stress, the minimum in a load-extension curve, the reversal of a load-extension curve, and the second ultimate stress.

Figure 9 shows results obtained with a plain 18:8 alloy. This is not the same as the alloy used in obtaining figures $1,2,4,5$, and 8 . As most of the experiments represented in figure 9 were made several years ago, the importance of determining values for both the first and second ultimate stresses was not realized. Complete curves for the first ultimate stress, therefore, could not be obtained. As indicated by the symbols along the two ultimate-stress curves in figure 9, part of each curve shows the influence of a range of temperature on the first ultimate stress, and part shows the influence of a lower range of temperature on the second ultimate stress. However, the experiments have been made at enough different temperatures to establish definitely the form of the curves of variation of the ultimate stress and fracture stress.

Figures 9 to 14 show the effect of temperature on the important strength indices. The effect of temperature on a strength index comprises the direct effect on the strength of the metal, and the superimposed effects on the amount of plastic deformation and the rate of hardening in the test made to determine the strength index. For the

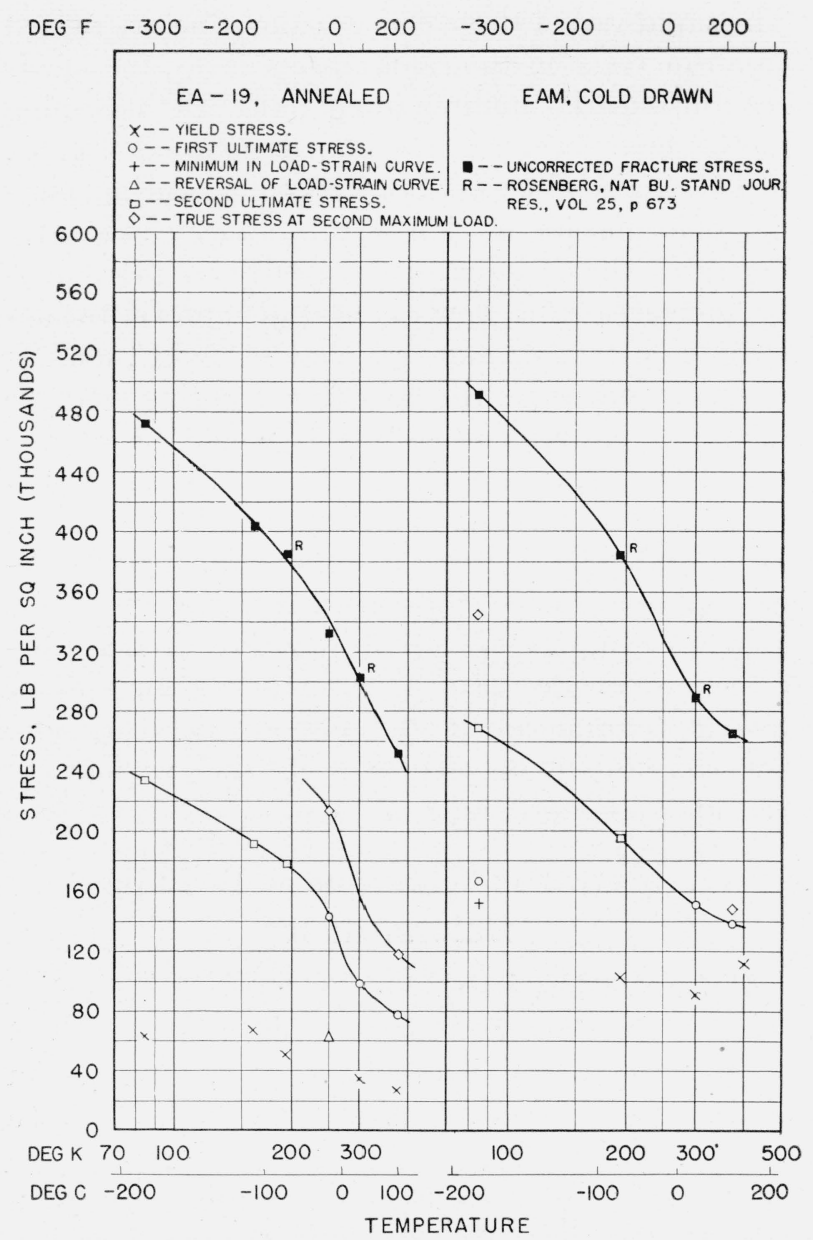

FIGURE 9. Variation of the strength of plain 18:8 chromiumnickel steels with temperature.

18:8 alloys, the superimposed indirect effects vary greatly with the temperature, and with the amount of plastic deformation required for determining the strength index. In studying the variation of the strength indices with temperature, consideration should be given to the relation between the direct and indirect effects of temperature on each index. The smaller the amount of plastic deformation required for determining the index, the less are the superimposed indirect effects, and the more nearly does the variation of the index with temperature represent the direct effect of temperature on the strength of the metal.

As the yield stress represents the strength of the metal at approximately the beginning of plastic strain, the influence of temperature in this index generally represents approximately the direct influence of temperature on the strength of the metal. The yield stresses of the 18:8 alloys at 


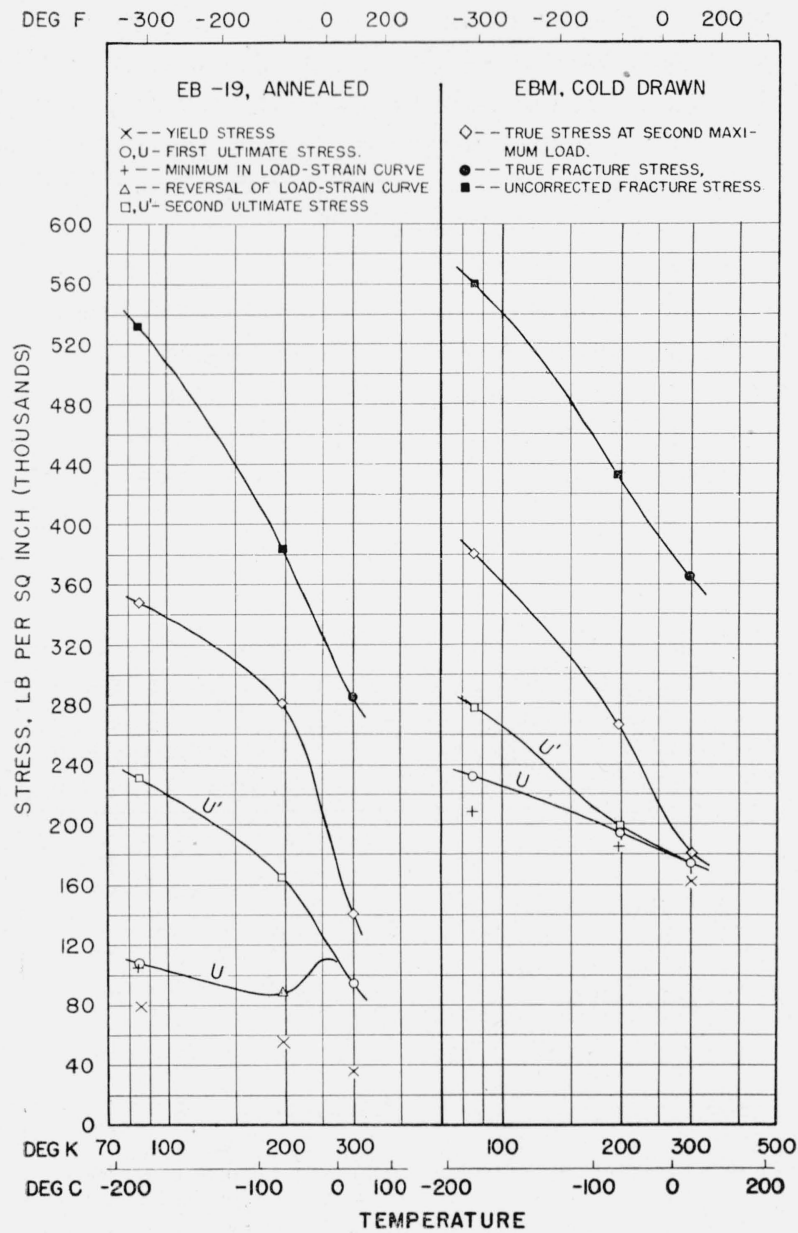

Figure 10. Variation of the strength of plain 18:8 chromium-nickel steels with temperature.

room temperature were determined by means of transverse measurements during the tension tests. At low temperatures, the yield stresses were determined by means of the automatic load-extension diagrams. Because of the indefiniteness of the yield stress of the metastable austenitic alloys, the values obtained from the automatic diagrams are only approximately correct.

As shown in figures $9,10,12,13$, and 14 , the increase in the yield stress with decrease in temperature is less rapid than the increase of any other index except the first ultimate stress. As would be expected, however, the greater the amount of prior plastic deformation, the less do the indices of resistance to plastic deformation diverge with decrease in temperature. After severe prior plastic deformation, the curves for the first and second ultimate stresses nearly coincide, as shown in the diagram for alloy $E B N$ in figure 11.
The yield stress of the ferritic alloy (fig. 11) rises much more rapidly with decrease in temperature than the yield stress of the metastable austenitic alloys (figs. 9 to 14); the rise is about as rapid as for a carbon steel. As shown in a previous paper [8], a rapid increase of the yield stress with decrease in temperature is associated with a rapid decrease in ductility.

Next to the yield stress the first ultimate stress is the most suitable index for revealing the direct influence of temperature on the strength of an 18:8 alloy. However, when the nominal-stress versus extension curve merely reverses curvature without traversing a maximum, the nominal stress at the reversal may be used for the same purpose, and is nearly as satisfactory as the first ultimate stress. In some of the diagrams, it was possible to establish complete curves for both the first and second ultimate stresses. The relation between these

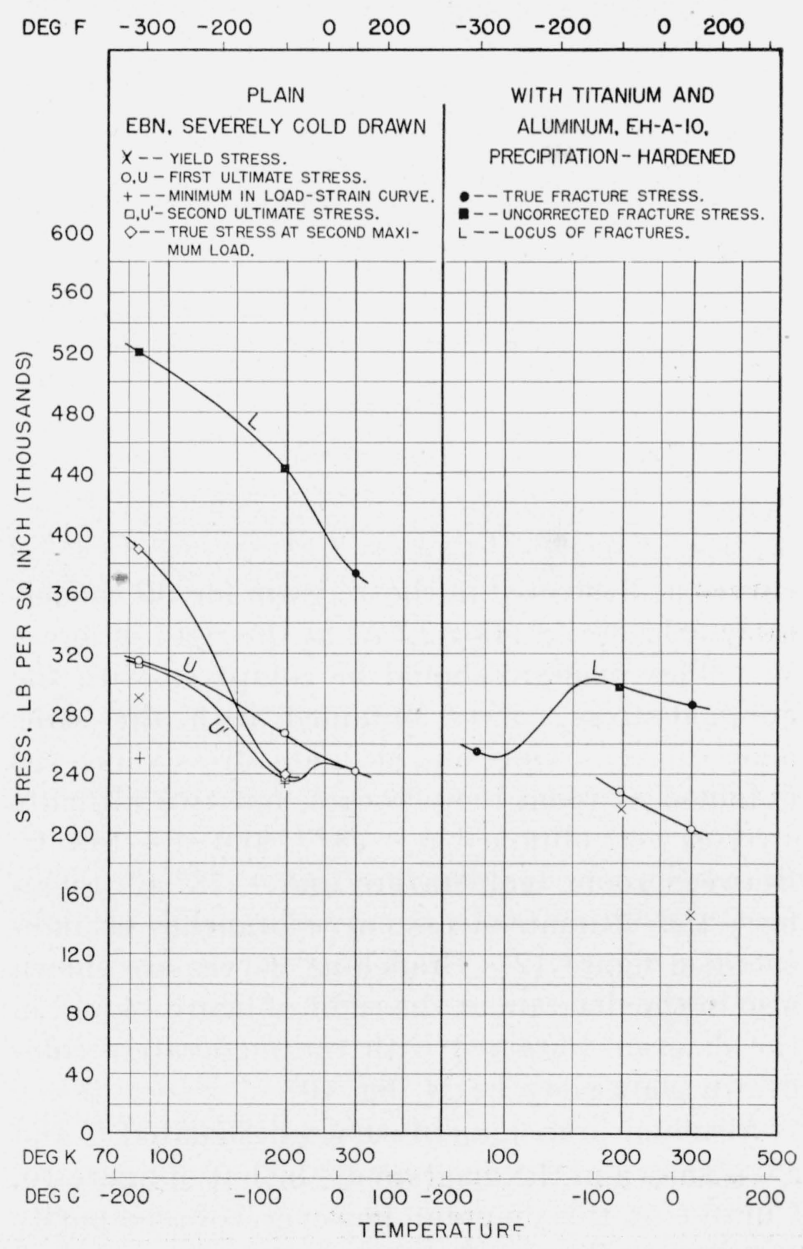

FIGURE 11. Variation of the strength of 18:8 chromiumnickel steels with temperature. 


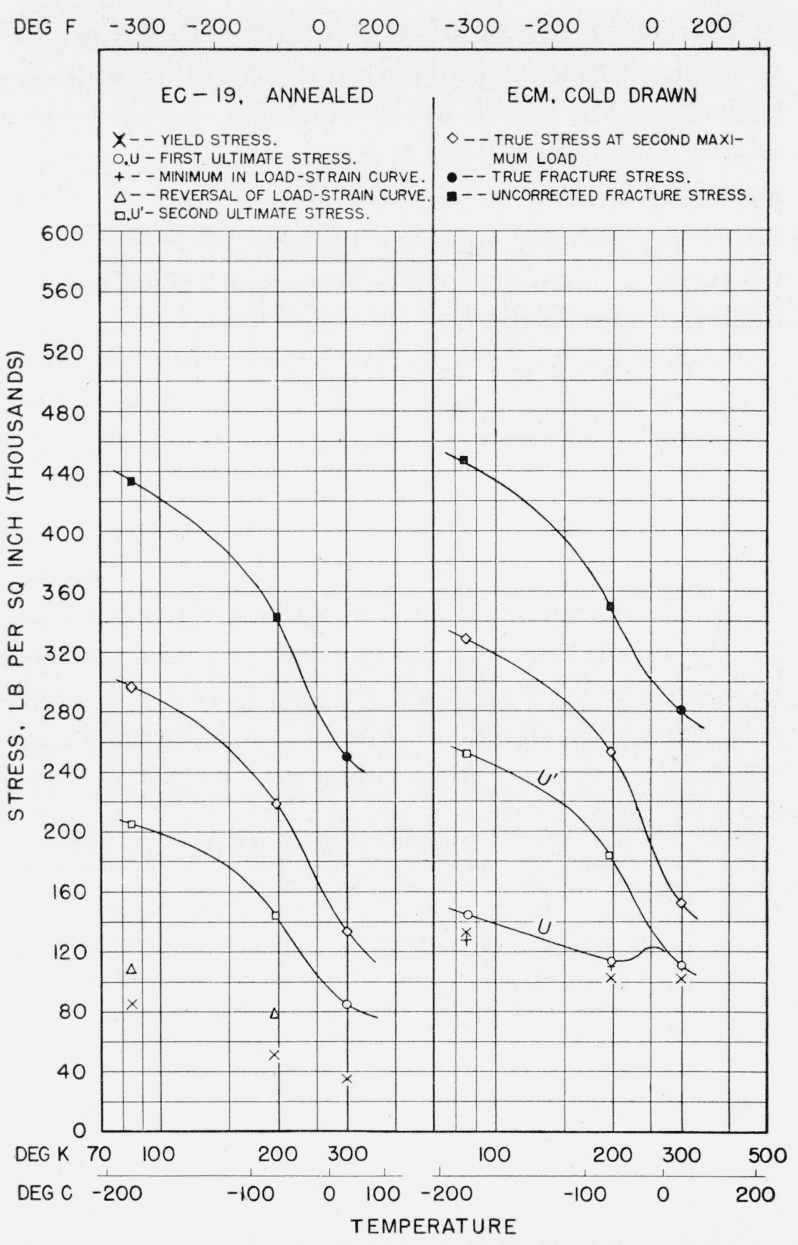

FIGURE 12. Variation of the strength of 18:8 chromiumnickel steels containing titanium with temperature.

curves is illustrated in the diagram for the moderately cold-drawn alloy ECM at the right of figure 12. This diagram should be compared with the nominal-stress curves obtained with the same alloy (fig. 3). Only one ultimate-stress value was obtained at room temperature, but two ultimate stresses were obtained at $-78^{\circ} \mathrm{C}$ and at $-188^{\circ} \mathrm{C}$. Between room temperature and $-78^{\circ} \mathrm{C}$, therefore, the ultimate-stress curve branches as indicated in figure 12. Branching curves are shown also in the diagram at the right of figure 14 and in the diagram obtained with the moderately colddrawn plain alloy EBM (fig. 10).

A similar branching of curves designated $U$ and $U^{\prime}$ is shown in the diagram at the left of figure 10 . Curve $U$ in this diagram, however, is based partly on the small triangle representing the nominal stress at the point of reversal of the load-strain curve obtained at $-78^{\circ} \mathrm{C}$. As illustrated by the corresponding curve in figure 1 , the nominal-stress approached a maximum, but rapid precipitationhardening caused a reversal of curvature before a maximum was attained. The point of reversal of curvature $(R E)$ evidently was very little higher than the maximum that would have been attained in the absence of the rapid phase change. Consequently, use has been made of the nominal stress represented by point $R E$ in establishing curve $U$ in figure 10 to represent as nearly as possible the direct influence of temperature on the strength of the annealed metal. A similar method has been used in deriving curve $U$ in the diagram at the left of figure 13. A curve of similar form and significance could be based on the two small triangles

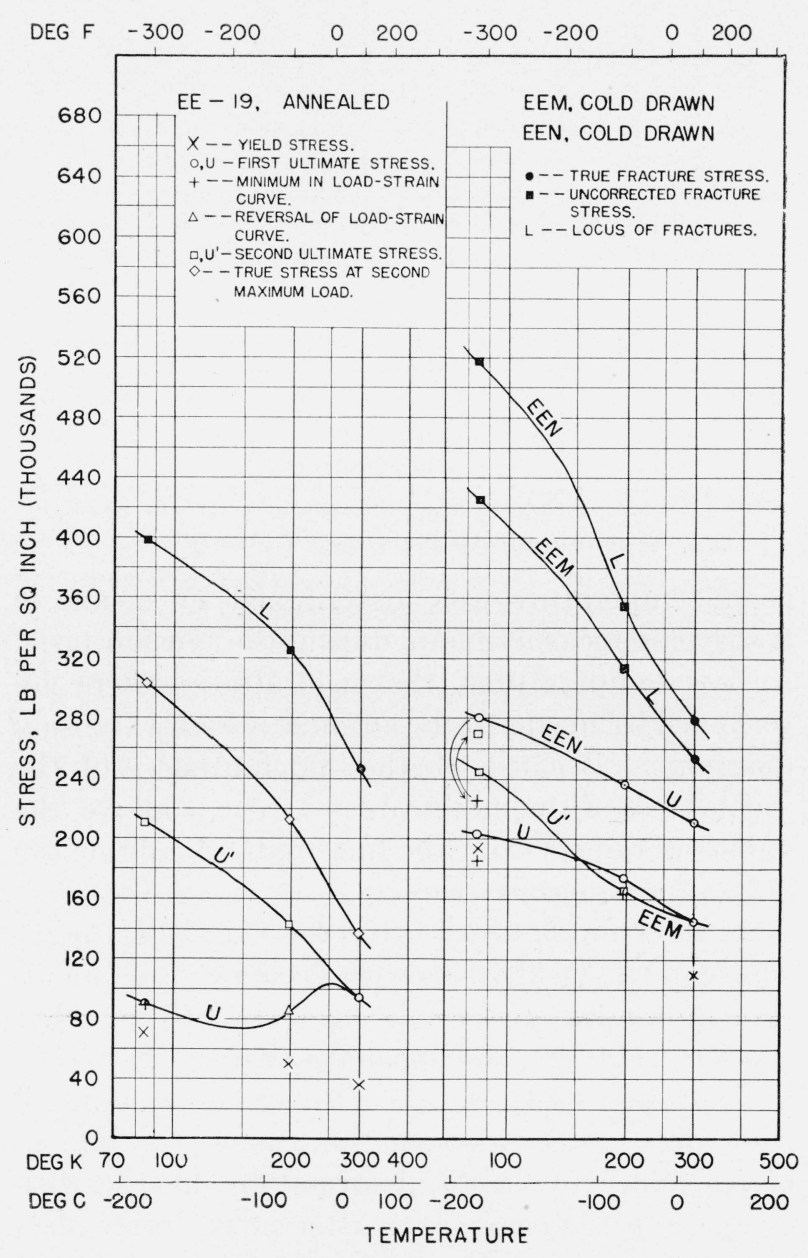

Figure 13. Variation of the strength of 18:8 chromiumnickel steels containing columbium with temperature. 


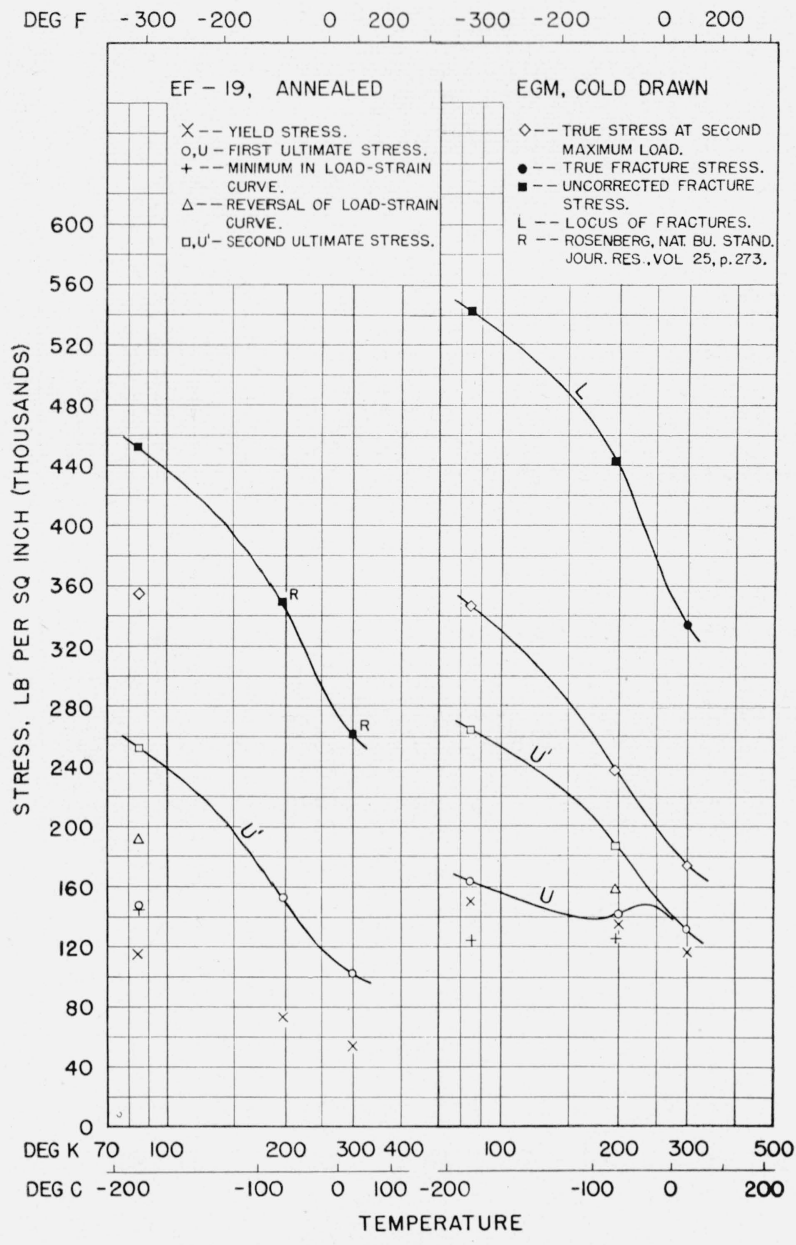

FIgURE 14. Variation of the strength of 18:8 chromiumnickel steels containing molybdenum with temperature.

in the diagram for the annealed alloy, at the left of figure 12 .

Only the nearly straight part of curve $U$, however, represents approximately the direct effect of temperature on the strength of the metal. The upward bulge of the curve in a diagram for annealed metal or for moderately cold-drawn metal (figs. 10, 12, 13, and 14) is due to the superimposed effect of temperature on the strain necessary for the load to reach a maximum. As shown in the diagram for the annealed plain alloy $E B-19$ (fig 1), the strain necessary for the load to reach a maximum was much greater at room temperature than at low temperatures. This diagram should be compared with curve $U$ in the diagram at the left of figure 10. A similar relationship is revealed by a comparison of the diagram at the right of figure 3 with curve $U$ in the diagram at the right of figure 12 , and by a comparison of the diagram at the left of figure 7 with curve $U$ in the diagram at the right of figure 14. The upward bulge in curve $U$ in diagrams for annealed alloys or for moderately cold-drawn alloys, therefore, is due to hardening of the metal during the relatively great plastic deformation necessary for the load to reach a maximum.

When the prior cold-work has been severe, the strain necessary for the load to reach a maximum is about as small at room temperature as at low temperatures. Illustrations of this relationship are shown in figure 2 and in the diagram at the left of figure $3 .^{6}$ As the plastic strain at the first maximum load was small at room temperature and at low temperatures, the corresponding curves $U$ in figures 10,11 , and 13 are practically free from effects of variable plastic deformation. Unlike the curves obtained with the less severely coldworked alloys or with the annealed alloys, these curves rise continuously with decrease in temperature. If yield-stress curves were drawn in these figures, their slopes would differ little from the slopes of curves $U$ and from the slopes of the nearly straight parts of the curves $U$ obtained with the softer alloys. These slopes represent approximately the direct effect of temperature on the strength of the 18:8 chromium-nickel steels.

All the curves of the variation of the second ultimate stress with temperature are affected by the phase changes induced by plastic deformation. In the absence of the rapid phase changes at low temperatures there would be no second ultimate stress. The divergence of curves $U$ and $U^{\prime}$ is greatest for the annealed metals, and decreases with increase in the amount of prior cold-work. The influence of the rapid phase change at low temperatures is revealed most prominently by the steep rise of the curves representing the influence of temperature on the true stress at the second maximum and on the fracture stress. The course of each of these curves, however, indicates that with decrease in temperature below that of liquid air the influence of temperature on these strength indices gradually decreases.

\footnotetext{
${ }_{6}^{6}$ Comparison of ultimate stresses shows that the prior cold-work was more severe for these three alloys and for alloy EEN (fig. 13) than for any of the other alloys used in the investigation.
} 


\section{Variation of Strength of 18:8 Chromium-Nickel Steel and of Some Other Metals Between Room Temper- ature and $-252.8^{\circ} \mathrm{C}$}

The only extensive investigation of the mechanical properties of metals at the temperature of liquid hydrogen was by DeHaas and Hadfield [4]. Steels of many different compositions and a few nonferrous metals were included in their investigation. Only two chromium-nickel stainless steels were used. One was an 18:8 chromium-nickel steel; the other was a stable austenitic steel containing 14.4 percent of chromium and 59.3 percent of nickel. Yield stresses, ultimate stresses, and ductility values were determined at room temperature and at the temperature of liquid hydrogen, but fracture stresses were not determined.

In figure 15, results obtained by DeHaas and Hadfield at room temperature and at $-252.8^{\circ} \mathrm{C}$ are compared with results obtained at the National Bureau of Standards within the range between room temperature and $-188^{\circ} \mathrm{C}$. The diagram shows results obtained by DeHaas and Hadfield with monel metal, electrolytic copper, the 18:8 alloy, and the stable austenitic chromium-nickel steel. For comparison, curves obtained with monel metal and oxygen-free copper have been reproduced from a paper by McAdam and Mebs [6], and two curves obtained with the annealed plain 18:8 alloy EA-19 have been reproduced from figure 9 . With the exception of the fracturestresses derived from figure 9, only ultimate stresses are represented in figure 15 .

With the 18:8 chromium-nickel steel and the stable austenitic steel, DeHaas and Hadfield, obtained almost identical results at room temperature. At $-252.8^{\circ} \mathrm{C}$, however, the ultimate stress of the 18:8 alloy was about 50 percent greater than that of the stable austenitic alloy. The strength index reported for the 18:8 alloy at this temperature undoubtedly is the second ultimate stress. The ultimate-stress curve obtained with the 18:8 alloy $E A-19$ has been prolonged with little change of curvature, so as to pass through the point representing the result obtained by DeHaas and Hadfield with an alloy of the same type.

Moreover, the fracture-stress curve obtained with alloy $E A-19$ has been prolonged with little change of curvature, so that an approximate estimate may be made of the probable breaking

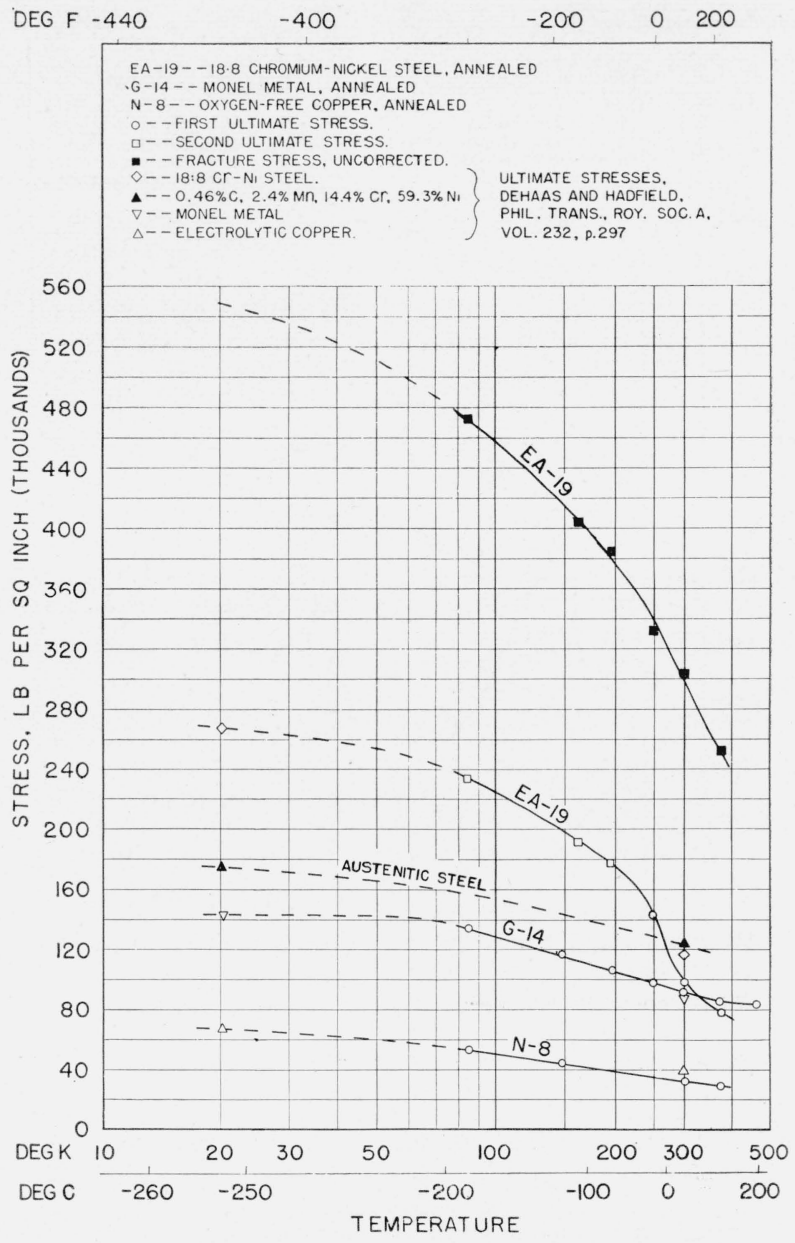

Figure 15. Variation of the strength of various metals with temperature.

stress of this alloy at the temperature of liquid hydrogen. The value thus obtained is of the same order as the breaking stresses of some of the 18:8 alloys in liquid air (figs. 10, 11, 13, and $14)$.

As shown in previous papers $[6,8,9]$, and as illustrated in figure 15 by the curves for monel metal $G-14$ and copper $N-8$, the variation of the strength indices for many nonferrous metals on this temperature scale is nearly linear between room temperature and $-188^{\circ} \mathrm{C}$. The results reported by DeHaas and Hadfield, however, indicate that the linear relationship does not continue between the temperatures of liquid air and liquid hydrogen. Although some of the reported ultimate stresses at the temperature of liquid hydrogen may be too low, the evidence indicates that the curves for the nonferrous metals and the stable austenitic alloy differ greatly in slope from the 
curve obtained with the 18:8 alloy. The evidence also indicates that the great difference in strength of these chromium-nickel alloys at the temperature of liquid air is due to a difference in the stability of the austenite. The austenite in the alloy containing 14.4 percent of chromium and 59.3 percent of nickel evidently retains its stability during plastic deformation at the temperature of liquid hydrogen.

If curves to represent the variation of the first ultimate stress of the metastable austenitic alloys with temperature were included in figure 15 , the slope between room temperature and $-188^{\circ} \mathrm{C}$ would differ little from the slopes of the curves obtained with monel metal and copper, and from the probable slope of a curve obtained with the stable austenitic steel. The slopes of these curves represent approximately the direct effect of temperature on the strength of the metals. The difference between these slopes and the slope of the curves for the 18:8 alloy is due to the superimposed effect of the variation in the amount of phase-change with temperature. This variation becomes less with decrease in temperature as the proportion of untransformed austenite remaining after deformation of the specimen in the tensile test becomes less as the temperature is lowered. As the temperature approaches that of liquid air, possibly all or nearly all of the austenite is transformed to ferrite by the plastic deformation.

\section{Influence of Notches on Mechanical Properties}

Figure 16 shows the results of a brief investigation of the influence of notches on the strength indices of 18:8 alloys throughout a range between room temperature and $-188^{\circ} \mathrm{C}$. The alloys used in obtaining these two diagrams are the same that were used in obtaining the diagram at the left of figure 11 and the diagram at the right of figure 12 . The curves representing results obtained with unnotched specimens are the same in figure 16 as in the corresponding diagrams of figures 11 and 12 . A slight distinction between the first and second ultimate stresses could be observed in some specimens with $150^{\circ}$ notch angle, but no distinction could be made when the angle was smaller.

Even when the angle was $50^{\circ}$, however, the plastic strain necessary for the load to reach a

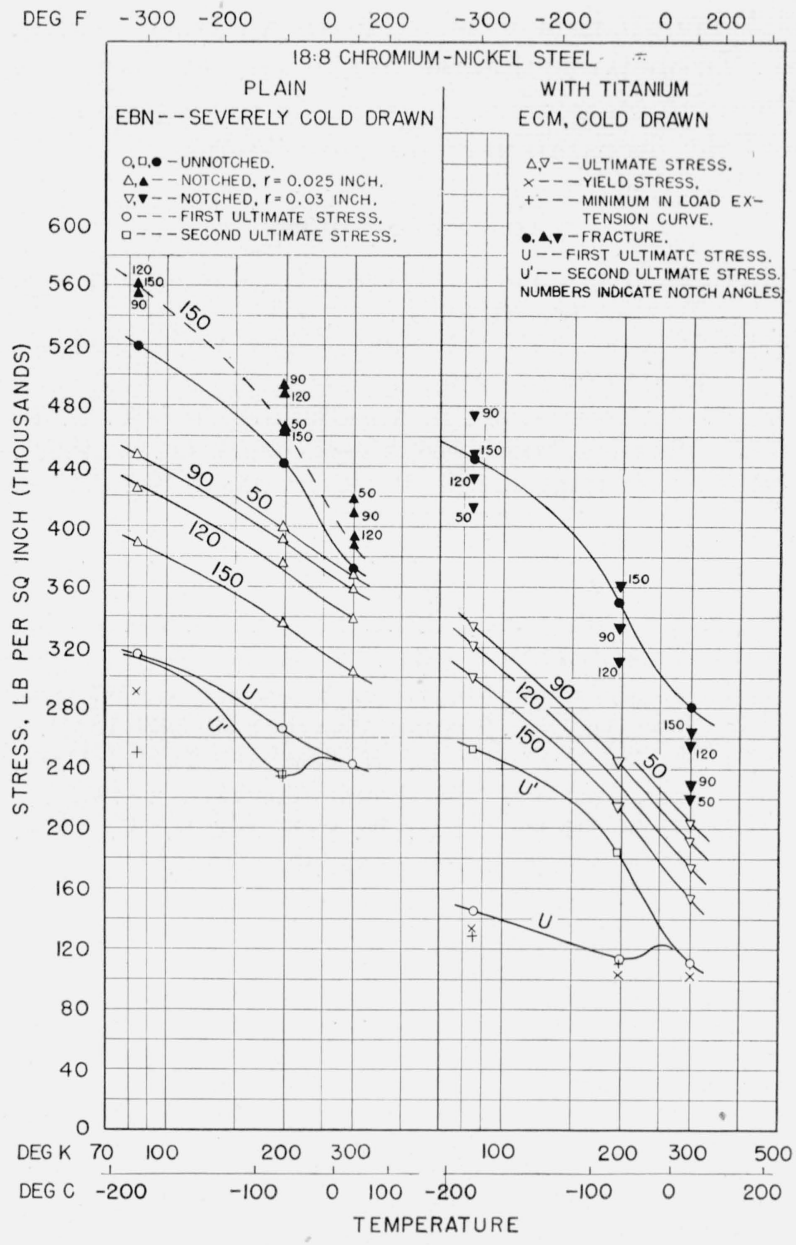

Figure 16. Combined influences of notches and low temperatures on the tensile properties of 18:8 chromiumnickel steel.

maximum at low temperatures was more than that for an unnotched specimen at the first maximum. Although the ductility decreased with decrease in the notch angle and with decrease in temperature, the combined influence of these two variables on the ductility was less for the 18:8 alloys than for pearlitic steels. At $-188^{\circ} \mathrm{C}$, the strain at fracture of a $50^{\circ}$ specimen was about 26 percent $\left(A_{0} / A=1.26\right)$. Moreover, the breaking stress of this specimen at $-188^{\circ} \mathrm{C}$ was high, although the specimen fractured before the tensile load reached a maximum. These unusual properties suggest that the ultimate stresses of the notched specimens were appreciably increased by the phase change during plastic deformation. This phase change evidently contributes to the toughness of both notched and unnotched specimens. 
Acknowledgment is made to D. H. Woodard, W. D. Jenkins, Fannie Wilkinson, and Lavaria Weinrich for general assistance in the experiments and the preparation of the illustrations.

\section{References}

[1] R. H. Aborn and E. C. Bain, Trans. Am. Soc. Steel Treating 18, 837 (1930).

[2] J. B. Austin and O. S. Miller, Trans. Am. Soc. Metals 28, 743 (Sept. 1940).

[3] E. W. Colbeck, W. E. MacGillivray, and W. R. D. Manning, Trans. Inst. Chem. Engrs. 11, 89 (1933).

[4] W. J. DeHaas and Sir Robert Hadfield, Phil. Trans. Roy. Soc. [A] 232, 297 (1933 to 1934).

[5] V. N. Krivobok and R. A. Lincoln, Trans. Am. Soc. Metals 25, 637 (1937).

[6] D. J. McAdam, Jr. and R. W. Mebs, Am. Soc. Testing Materials 43, 661 (1944).

[7] D. J. McAdam, Jr., R. W. Mebs, and G. W. Geil, Proc. Am. Soc. Testing Materials 44, 593 (1944).

[8] D. J. McAdam, Jr., G. W. Geil, and R. W. Mebs, Proc. Am. Soc. Testing Materials 45, 448 (1945).

[9] D. J. McAdam, Jr., G. W. Geil, and R. W. Mebs, Trans. Am. Soc. Metals 37, 497 (1946).
[10] D. J. McAdam, Jr., G. W. Geil, and R. W. Mebs, Am. Inst. Mining Met. Engrs., Tech. Pub. 2220, Metals Technology, (August 1947).

[11] D. J. McAdam, Jr., G. W. Geil, and W. D. Jenkins, Proc. Am. Soc. Testing Materials 47, 554 (1947).

[12] D. J. MeAdam, Jr., G. W. Geil, and Frances Jane Cromwell, Am. Inst. Mining Met. Engrs., Tech. Pub. 2296, Metals Technology (Jan. 1948).

[13] N. B. Pilling, Proc. Am. Soc. Testing Materials Part 2, 30, 278 (1930).

[14] L. B. Pfeil and D. G. Jones, J. Iron Steel Inst. 127, No. 1, 337 (1933).

[15] C. B. Post and W. S. Eberly, Trans. Am. Soc. Metals 39, 868 (1947).

[16] S. J. Rosenberg, NBS J. Research 25, 673 (1940) RP 1347.

[17] R. Smith, E. H. Wycke, and W. W. Gorr, Am. Inst. Mining Met. Engrs., Tech. Pub. 2006, Metals Technology (June 1946); Trans. Am. Inst. Mining Met. Engrs. 167, 313 (1946).

[18] E. E. Thum, The book of stainless steels (Am. Soc. Metals, Cleveland, Ohio, 1935).

[19] H. H. Uhlig, Trans. Am. Soc. Metals 30, 947 (1942).

WAShington, January 2, 1948. 